\title{
The Natural Rate of Interest and its Usefulness for Monetary Policy
}

Robert Barsky, Alejandro Justiniano, and Leonardo Melosi

Online Appendix 


\section{Introduction}

This appendix describes the extended DSGE model that we used to estimate the dynamics of the natural rate of output in the article. The model is built on Smets and Wouters (2007) with only a few departures from it that include the specification of the monetary policy rule, the forward guidance as in Campbell et al. (2012) and Campbell, Fisher and Justiniano (2012), and the measurement equations.

This appendix is organized as follows. Section 2 describes the problem of household in this economy. Sections 3 and 4 deal with the problems of the final goods producers and the intermediate goods producers, respectively. In Section 5 we present the labor sector. The interest rate rule followed by the central bank and how we model forward guidance are shown in Section 6 . Section 7 discusses the behavior of the fiscal authority. In Section 8, the measurement equations are detailed.

\section{Households}

Household $j$ chooses consumption $C_{t}(j)$, hours worked $L_{t}(j)$, bonds $B_{t}(j)$, investment $I_{t}(j)$, capital $K_{t}(j)$, and capital utilization $Z_{t}(j)$ so as to maximize the following objective function:

$$
E_{t} \sum_{s=0}^{\infty} \beta^{s}\left[\frac{1}{1-\sigma_{c}}\left(C_{t+s}(j)-\lambda C_{t+s-1}\right)^{1-\sigma_{c}}\right] \exp \left(\frac{\sigma_{c}-1}{1+\sigma_{l}} L_{t+s}(j)^{1+\sigma_{l}}\right)
$$

subject to the flow budget constraint

$$
\begin{aligned}
C_{t+s}(j)+ & I_{t+s}(j)+\frac{B_{t+s}(j)}{\varepsilon_{t+s}^{l} R_{t+s} P_{t+s}}+T_{t+s} \\
\leq \frac{B_{t+s-1}(j)}{P_{t+s}}+\frac{W_{t+s}^{h}(j) L_{t+s}(j)}{P_{t+s}}+\frac{R_{t+s}^{k} Z_{t+s}(j) K_{t+s-1}(j)}{P_{t+s}} & -a\left(Z_{t+s}(j)\right) K_{t+s-1}(j)+\frac{D i v_{t+s}}{P_{t+s}}
\end{aligned}
$$

the capital accumulation equation

$$
K_{t}(j)=(1-\delta) K_{t-1}(j)+\varepsilon_{t}^{i}\left[1-S\left(\frac{I_{t}(j)}{I_{t-1}(j)}\right)\right] I_{t}(j)
$$


and the amount of effective capital rented to firms,

$$
K_{t}^{s}(j)=Z_{t}(j) K_{t-1}(j) .
$$

Note that there is no separability between consumption and leisure in the utility function. There are two exogenous processes related to the household. The first, $\varepsilon_{t}^{i}$, represents a shock to the price of investment relative to consumption goods:

$$
\ln \varepsilon_{t}^{i}=\rho_{i} \ln \varepsilon_{t-1}^{i}+\eta_{t}^{i}, \eta_{t}^{i} \sim N\left(0, \sigma_{i}\right) .
$$

The second, $\varepsilon_{t}^{l}$, is an exogenously-determined wedge in the return to bond (with respect to the interest rate set by the central bank), which may reflect inefficiencies in the financial sector:

$$
\ln \varepsilon_{t}^{l}=\rho_{l} \ln \varepsilon_{t-1}^{l}+\eta_{t}^{l}, \eta_{t}^{l} \sim N\left(0, \sigma_{l}\right) .
$$

\section{$3 \quad$ Final Goods Producers}

Final goods producers create a composite final good $Y_{t}$ which is made of a continuum of intermediate goods $Y_{t}(i)$. The final goods producers maximize profits:

$$
\begin{gathered}
\max _{Y_{t}, Y_{t}(i)} P_{t} Y_{t}-\int_{0}^{1} P_{t}(i) Y_{t}(i) d i, \\
\text { s.t. }\left[\int_{0}^{1} Y_{t}(i)^{\frac{1}{1+\lambda_{p, t}}} d i\right]^{1+\lambda_{p, t}}=1,
\end{gathered}
$$

where $P_{t}$ and $P_{t}(i)$ are the price of the final and intermediate goods respectively. $\lambda_{p, t}$ is the elasticity of demand, or the price mark-up. It is composed of a constant, $\lambda_{p}$ plus a shock $\varepsilon_{t}^{p} \in(0, \infty)$ that follows an exogenous process:

$$
\ln \lambda_{p, t}=\left(1-\rho_{p}\right) \ln \lambda_{p}+\rho_{p} \ln \lambda_{p, t-1}-\theta_{p} \eta_{t-1}^{p}+\eta_{t}^{p}, \eta_{t}^{p} \sim N\left(0, \sigma_{p}\right) .
$$

\section{Intermediate Goods Producers}

Intermediate goods producer $i$ produces $\dot{Y}_{t}(i)$ using the following technology:

$$
\dot{Y}_{t}(i)=\varepsilon_{t}^{a} K_{t}^{s}(i)^{\alpha}\left[\gamma^{t} L_{t}(i)\right]^{1-\alpha}-\gamma_{t} \Phi
$$


where $\dot{Y}_{t}$ is intermediate output, $K_{t}^{s}(i)$ is effective capital used in production, $L_{t}(i)$ is labor input, $\Phi$ is a fixed cost, and $\gamma^{t}$ represents the labor-augmenting deterministic technology. This is the only trend in this economy. Finally, $\varepsilon_{t}^{a}$ is the total factor productivity that evolves according to the below:

$$
\ln \varepsilon_{t}^{a}=\left(1-\rho_{a}\right) \ln \varepsilon^{a}+\rho_{a} \ln \varepsilon_{t-1}^{a} \eta_{t}^{a}, \eta_{t}^{a} \sim N\left(0, \sigma_{a}\right) .
$$

The cost minimization problem for intermediate goods firms reads as follows:

$$
\max _{L_{t}(i), K_{t}^{s}(i)}-W_{t} L_{t}(i)-R_{t}^{k} K_{t}^{s}(i)
$$

where $W_{t}$ is the aggregate nominal wage rate and $R_{t}^{k}$ is the rental rate on capital.

Those firms that are allowed to re-optimize their price solve the following price-setting problem:

$$
\begin{gathered}
\max _{\tilde{P}_{t}(i)} E_{t} \sum_{s=0}^{\infty} \zeta_{p}^{s} \frac{\beta^{s} \Lambda_{t+s}^{1} P_{t}}{\Lambda_{t}^{1} P_{t+s}}\left[\tilde{P}_{t}(i) X_{t, s}^{y}-M C_{t+s}\right] Y_{t+s}(i), \\
\text { s.t. } Y_{t}(i)=\left(X_{t, s}^{y} \frac{P_{t}(i)}{P_{t}}\right)^{-\frac{1+\lambda_{p, t}}{\lambda_{p, t}}} Y_{t}, \\
\text { where } X_{t, s}^{y}=\left\{\begin{array}{ll}
1 & : s=0 \\
\prod_{l=1}^{s} \pi_{t+l-1}^{\iota_{p}} \pi^{* 1-\iota_{p}} & : s=1, \ldots, \infty
\end{array}\right\} .
\end{gathered}
$$

\section{Labor Sector}

In the labor sector, the labor unions purchase labor from the households at the common wage $W_{t}^{h}$ and sell the differentiated labor, $L(l)$ to the labor packer $l$ at the wage $W_{t}(l)$. Labor unions set prices following a Calvo Pricing scheme. Then, the labor packers sell the aggregate labor, $L_{t}$, to the intermediate goods producers at the wage $W_{t}$.

\subsection{Labor Packers}

It is easier to begin by studying the decision problem facing the labor packers. Labor packers buy labor from the unions, $L_{t}(l)$, package it into composite labor $L_{t}$, and sell it to the intermediate goods producers. They 
maximize profits in a perfectly competitive environment, so their decision problem is as follows:

$$
\begin{gathered}
\max _{L_{t}, L_{t}(i)} W_{t} L_{t}-\int_{0}^{1} W_{t}(l) L_{t}(l) d l \\
\text { s.t. }\left[\int_{0}^{1} L_{t}(l)^{\frac{1}{1+\lambda} w, t} d l\right]^{1+\lambda_{w, t}}=1
\end{gathered}
$$

We also assume that $\lambda_{w, t}$, is composed of a constant, $\lambda_{w}$, and an exogenous ARMA process, $\lambda_{t}^{w}$ :

$$
\ln \lambda_{t}^{w}=\left(1-\rho_{w}\right) \ln \lambda^{w}+\rho_{w} \ln \lambda_{t-1}^{w}-\theta_{w} \eta_{w, t-1}+\eta_{w, t}, \eta_{w, t} \sim N\left(0, \sigma_{w}\right)
$$

\subsection{Labor Unions}

We can then set the maximization problem for the labor unions as follows:

$$
\begin{gathered}
\max _{\tilde{W}_{t}(l)} E_{t} \sum_{s=0}^{\infty} \zeta_{w}^{s}\left[\frac{\beta^{s} \Lambda_{t+s}^{1} P_{t}}{\Lambda_{t}^{1} P_{t+s}}\right]\left[X_{t+s}^{l} \tilde{W}_{t}(l)-W_{t+s}^{h}\right] L_{t+s}(l) \\
\text { s.t. } L_{t+s}(l)=\left(\frac{X_{t+s}^{l} \tilde{W}_{t}(l)}{W_{t+s}}\right)^{-\frac{1+\lambda_{w, t+s}}{\lambda_{w, t+s}}} L_{t+s}
\end{gathered}
$$

$$
\text { where } X_{t, s}^{l}=\left\{\begin{array}{ll}
1 & : s=0 \\
\prod_{j=1}^{s}\left(\pi_{t+j-1}\right)^{\iota w}\left(\pi_{*}\right)^{1-\iota_{w}} & : s=1, \ldots, \infty
\end{array}\right\} \text {, }
$$

where $\pi_{*}$ is the steady-state inflation rate.

\section{Monetary Authority}

The central bank follows a nominal interest rate rule:

$$
\frac{R_{t}}{R_{*}}=\left(\frac{R_{t-1}}{R_{*}}\right)^{\rho_{R}}\left[\left(\frac{\prod_{i=-2}^{1}\left(\pi_{t+i}\right)^{\frac{1}{4}}}{\pi_{*}} \frac{\pi_{t}^{d}}{\pi_{*}}\right)^{\psi_{1}}\left(\frac{\prod_{i=-2}^{1}\left(\frac{Y_{t+i}}{A_{t+i}}\right)^{\frac{1}{4}}}{Y_{*}}\right]^{\psi_{2}}\right]^{1-\rho_{R}} \prod_{j=0}^{M} \xi_{t-j, j}
$$


where $\pi_{t}^{d}$ is the new "inflation drift" variable, and $\prod_{j=0}^{M} \zeta_{t-j, j}$ are the $M+1$ shocks or signals.

The Inflation Drift is an $\mathrm{AR}(1)$ process:

$$
\ln \pi_{t}^{d}=\rho_{\pi^{d}} \ln \pi_{t-1}^{d}+\eta_{t}^{d}
$$

The forward guidance shocks, $\sum_{j=0}^{M} \xi_{t-j, j}$, are a series of $M+1$ disturbances, $\xi_{t-j, j}$, revealed at different points in time. For $j=0$, this is the standard contemporaneous monetary policy shock. for $j>0$, these are signals of future policy. revealed in period $t-j$, that apply to the rule at $(t-j)+j=t$. They can be considered deliberate future deviations from "normal policy".

At each period $t$, the vector of forward guidance signals revealed is $\Xi_{t} \equiv$ $\left(\xi_{t, 0}, \xi_{t, 1}, \ldots, \xi_{t, M}\right)$. Consistent with the assumption that the signals represent news regarding the future conduct of monetary policy, $\Xi_{t}$ and $\Xi_{t-s}$ are assumed uncorrelated for $s \neq 0$. However, we allow for rich cross-sectional correlations within the elements of $\Xi_{t}$. In particular, the variance-covariance matrix of $\Xi_{t}$ can be parsimoniously allowed to be non-diagonal, using a factor structure. To this end, each signal in $\Xi_{t}$ has a representation:

$$
\xi_{t, j}=A_{j} f_{t}^{T}+B_{j} f_{t}^{P}+u_{t, j}
$$

The target factor, $f_{t}^{T}$, the path factor, $f_{t}^{P}$, and the idiosyncratic disturbances, $u_{t, j}$ are i.i.d. We use a hierarchical structure as an identifying restriction such that $A_{0}=1, B_{0}=0$, and $B_{i}=1$ for some $i>0$. We refer to $f_{t}^{T}$ as the target factor since it is the only one of the two common components that captures unexpected innovations to the current federal funds rate $\left(B_{0}=0\right)$. The path factor, $f_{t}^{P}$, represents therefore the common component of revisions to future path of the federal funds rate that is orthogonal to surprises in the current rate.

We estimate all the non-normalized loadings, as well as the std. deviations of the factors $\left(\sigma_{f_{C}}, \sigma_{f_{F}}\right)$ and of the idiosyncratic signals $\sigma_{u, j}$.

\section{Fiscal Authority}

The passive government purchases government spending $G_{t}$ though a mixture of bonds $B_{t-1}$ and nominal lump-sum taxes $T_{t}$.

$$
P_{t} G_{t}+B_{t-1}=T_{t}+\frac{B_{t}}{\varepsilon_{t}^{l} R_{t}} .
$$


Government spending expressed relative to steady state output path $g_{t}=$ $G_{t} /\left(Y \gamma^{t}\right)$ follows the process:

$$
\ln g_{t}=\left(1-\rho_{g}\right) \ln g+\rho_{g} \ln g_{t-1}+\varepsilon_{g, t}
$$

\section{Measurement Equations}

We estimate the model using data on per-capita GDP, consumption (of non-durables and services) and private investment (including durable consumption), as well as hours (in the non-farm business sector). These series are standard in the estimation of similar models, see for instance, Justiniano, Primiceri and Tambalotti (2010). The remaining series are less common in the empirical DSGE literature and arise form our multiple indicator approach, the inclusion of forward guidance and, the use of long-run expectations of inflation to inform the inflation drift. We briefly comment on each.

\subsection{Multiple Indicators}

Rather than matching the model's concepts of price and wage inflation to a single series, we use instead multiple measurements. More specifically, focusing on prices as an illustration, let

$$
\pi_{t}^{p \prime}=\left[\pi_{1, t}^{p}, \ldots, \pi_{L_{p}, t}^{p}\right]^{\prime}
$$

correspond to the vector of $L_{p}$ data series of quarterly price inflation. The measurement equation for the $j-t h$ element, $\pi_{j, t}^{p}$, links this series with the model concept of price inflation using a factor structure,

$$
\pi_{j, t}^{p}=\left(\bar{\pi}+c_{j}\right)+\Lambda_{j, t} \pi_{m, t}^{p}+u_{j, t}
$$

The steady state level of inflation, $\bar{\pi}$, is estimated, but we also allow a small discrepancy, $c_{j}$, in the order of 5 to 10 basis points per quarter, to account for differences in means across some series (we set $c_{j}=0$ for one $j$ ). The factor loading, $\Lambda_{j, t}$, and idiosyncratic disturbances, $u_{j, t}$, are series specific. The latter is allowed to follow an $\mathrm{AR}(1)$ process but is assumed uncorrelated with other series. Since this factor structure enters only the measurement equations, these disturbances do not affect any of the model's structural equations, nor the measurement of any other series used in estimation. We 
normalize $\Lambda_{j, t}=1$ for one $j=1, \ldots, L_{p}$. The same structure is used to map $L_{w}$ measurements of wage inflation to the model concept $\pi_{m, t}^{w}$.

In this paper we inform price inflation with the quarterly log-difference in the GDP deflator, PCE Core and CPI Core price indices $\left(L_{p}=3\right)$. For the case of wages, the two measurements $\left(L_{w}=2\right)$ correspond to hourly compensation in the non-farm business sector, and average hourly earnings of production and nonsupervisory workers in total private industries. These are the two series used in Gali, Smets and Wouters (2012) and Justiniano, Primiceri and Tambalotti (2013). As in Boivin and Giannoni (2006), using multiple indicators forces the model to match the common component of these series (either prices or wages), which tends to diminish the importance of price and wage markup shocks included in the structural equations.

\subsection{Forward Guidance}

As in Campbell et al. (2012) and Campbell, Fisher and Justiniano (2012), we use market-based expectations of the federal funds rate path to inform our estimates of forward guidance. Following the notation in (1), let $M$ correspond to the number of forward guidance signals that agents receive at each point in time. Then the measurement equations align the expected quarterly funds rate over the next $M$ quarters with the corresponding leads of the interest rate in the model,

$$
E_{t}\left[\begin{array}{llll}
\widehat{R}_{t+1} & \widehat{R}_{t+2} & \ldots & \widehat{R}_{t+M}
\end{array}\right]
$$

For the first two quarters, $t+1$ and $t+2$, the data come from federal funds rate futures contracts measured on the last day of each quarter. For the remaining horizons, ( $M=4$ until 2008q3, and, $M=12$ thereafter), we rely on Eurodollar futures until 2007 and Overnight Index Swaps (OIS) since then. There are no measurement errors in any of the interest rate measurement equations, including the contemporaneous one $\widehat{R}_{t}$, which is matched with the (average) effective federal funds rate.

\subsection{Long-Run Expected Inflation}

Data on long-run expected inflation help to anchor the behavior of the inflation drift, $\ln \pi_{t}^{d}$ in equation (2). To that end, we construct model-based 
expected inflation over the next 40 quarters

$$
\pi_{t, t+40}^{m}=\frac{1}{40} \sum_{s=1}^{40} E_{t} \pi_{t+s} .
$$

Using the median of expected CPI Inflation over the next 10 years from the Survey of Professional forecasters as the observable counterpart, $\pi_{t, t+40}$, the measurement equation is given by

$$
\pi_{t, t+40}=\left(\bar{\pi}+c_{40}\right)+\pi_{t, t+40}^{m}+\epsilon_{40, t} .
$$

As in the case of multiple price measurements, the small constant $c_{40}$ corrects for differences in means between expected and observed inflation. This is necessary in our case especially since $\bar{\pi}$ matches the sample mean of Core PCE, while the above data refer to the CPI. Finally $\epsilon_{40, t}$ is a small measurement error (in estimation its standard deviation is around 2 basis points). 


\section{References}

Boivin, J., and M. Giannoni. 2006. "DSGE Models in a Data-Rich Environment." NBER Working Paper, 0332.

Campbell, Jeffrey R., Charles Evans, Jonas D. M. Fisher, and Alejandro Justiniano. 2012. "Macroeconomic effects of Federal Reserve Forward Guidance." Brookings Papers on Economic Activity.

Campbell, Jeffrey R., Jonas D. M. Fisher, and Alejandro Justiniano. 2012. "Monetary Policy Forward Guidance and the Business Cycle." mimeo Federal Reserve Bank of Chicago.

Gali, Jordi, Frank Smets, and Rafael Wouters. 2012. "Slow Recoveries: A Structural Interpretation." Journal of Money, Credit and Banking, 44: $9-30$.

Justiniano, Alejandro, Giorgio E. Primiceri, and Andrea Tambalotti. 2010. "Investment Shocks and Business Cycles." Journal of Monetary Economics, 57(2): 132-45.

Justiniano, Alejandro, Giorgio E. Primiceri, and Andrea Tambalotti. 2013. "Is There a Tradeoff Between Inflation and Output Stabilization?" American Economic Journal: Macroeconomics, 1-31.

Smets, Frank R., and Raf Wouters. 2007. "Shocks and Frictions in U.S. Business Cycles: A Bayesian DSGE Approach." American Economic review, 97(3): 586-606. 